\title{
Power Quality Improvement of Three Phase System using Shunt Active Power Filter
}

\author{
Niklesh Das ${ }^{1}$, Prof. Sandeep Mude ${ }^{2}$ \\ Department of Electrical Engineering, KDK College of Engineering, Nagpur ${ }^{1,2}$
}

\begin{abstract}
A power quality issue basically deals with any occurrence manifested in current, voltage or frequency deviation that results in damage, upset or failure of end use equipment. The non-linearity in the properties of power electronics devices and the higher switching frequency are the main causes of power quality issue. Thus this paper deals with power quality improvement by shunt active power filter to eliminate voltage and load current harmonics and for reactive power compensation. A shunt active power filter based on the instantaneous active and reactive current component (Id - Iq) method is proposed to compensate first harmonic unbalance. A theoretical studies based on synchronous detection method is done in this paper and the simulation results are analyzed regarding the harmonics compensation. Simulations are carried out with PI controller for the (Id - Iq) control strategies for different voltage condition using MATLAB/ SIMULINK.
\end{abstract}

Keywords: Harmonic distortion, shunt active power filter, (p-q) and (Id-Iq) control strategies, PI controller.

\section{INTRODUCTION}

Most of the social and economic activity depends on electrical energy quality and efficiency. The use of nonlinear load generates current and voltage harmonics which detoriates the power quality. Thus mitigation of harmonics is necessary. The non-sinusoidal currents drown from the ac mains by the non-linear loads cause reactive power burden and excessive neutral current their by reducing efficiency of the system. Since the beginning of 1980's active power filters have been accepted as most common compensession method. The shunt connected active power filter with a self-controlled DC bus used for reactive power compensession in power transmission system. SAPF compensate load current harmonics by injecting equal but opposite harmonic compenseting current.

The work presented mainly focus on p-q and Id-Iq control strategies using PI controller and hysteresis controller. Instantaneous active and reactive theory (p-q theory) was introduce by H. Akagi, Kawakawa and Nabae in 1984. Both p-q and Id-Iq methods are compared for distorted main voltage conditions and the Id-Iq control method comes out to be superior in harmonic compensession performance. MATLAB software simulation is done in Simulink power system for analysis of the performance of compensession methods.

\section{SHUNT ACTIVE POWER FILTER CONFIGURATION}

The active filters operations are based on injection of harmonics required by load. Modern harmonic filters are superior in filtering performance, smaller in physical size and more flexible in application. The active filters are slightly inferior in cost and operating loss, compared to passive filter. To employ active power filter in three phase four wire system, we have used the configuration of three leg structure with the neutral conductor being connected to midpoint of DC link capacitor. The higher order harmonics generated in the eight switch configuration due to frequent switching of semiconductor devices can be eliminated by the use of RC high pass filter. The three leg six switch split capacitor configuration of SAPF suffers several shot comings:

1) Control circuit is somewhat complex.

2) Voltage of tow capacitor of split capacitor needs to be properly balanced.

3) Large DC link capacitors are required.

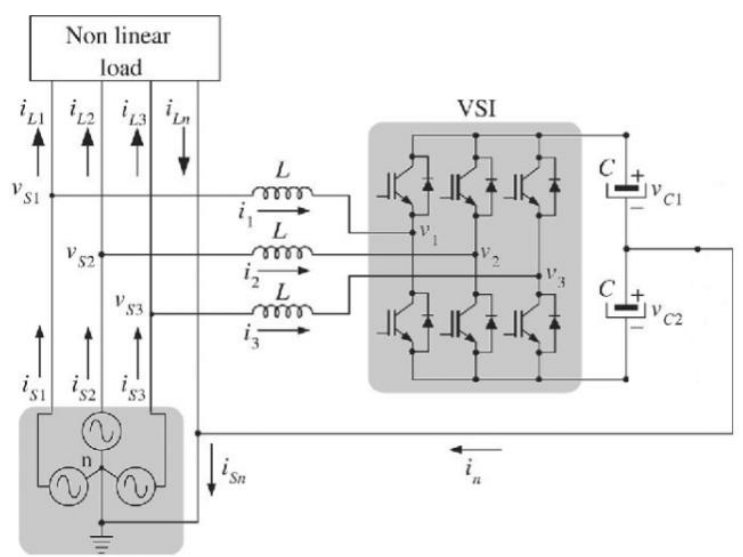

Figure (1): Three leg shunt active power filter with nonlinear load

\section{INSTANTANEOUS ACTIVE AND REACTIVE POWER (p-q) METHOD}

The control algorithm block diagram for p-q method is depicted in Figure (1). The three-phase source voltages 
Vol. 5, Issue 3, March 2017

$\left(\mathrm{v}_{\mathrm{sa}}, \mathrm{v}_{\mathrm{sb}}, \mathrm{v}_{\mathrm{sc}}\right)$ and load currents $\left(\mathrm{i}_{\mathrm{La}}, \mathrm{i}_{\mathrm{Lb}}, \mathrm{i}_{\mathrm{Lc}}\right)$ in the a-b-c coordinates are algebraically transformed to the $\alpha-\beta$ coordinates using Clarke's transformation as per (1) and (2), followed by the calculation of the instantaneous active power (p) and reactive power (q) by following (3).

$$
\left[\begin{array}{c}
\mathrm{v}_{\alpha} \\
\mathrm{v}_{\beta}
\end{array}\right]=\left[\begin{array}{ccc}
1 & \frac{1}{2} & \frac{1}{2} \\
0 & \frac{\sqrt{3}}{2} & -\frac{\sqrt{3}}{2}
\end{array}\right]\left[\begin{array}{c}
\mathrm{v}_{\mathrm{a}} \\
\mathrm{v}_{\mathrm{b}} \\
\mathrm{v}_{\mathrm{c}}
\end{array}\right]
$$

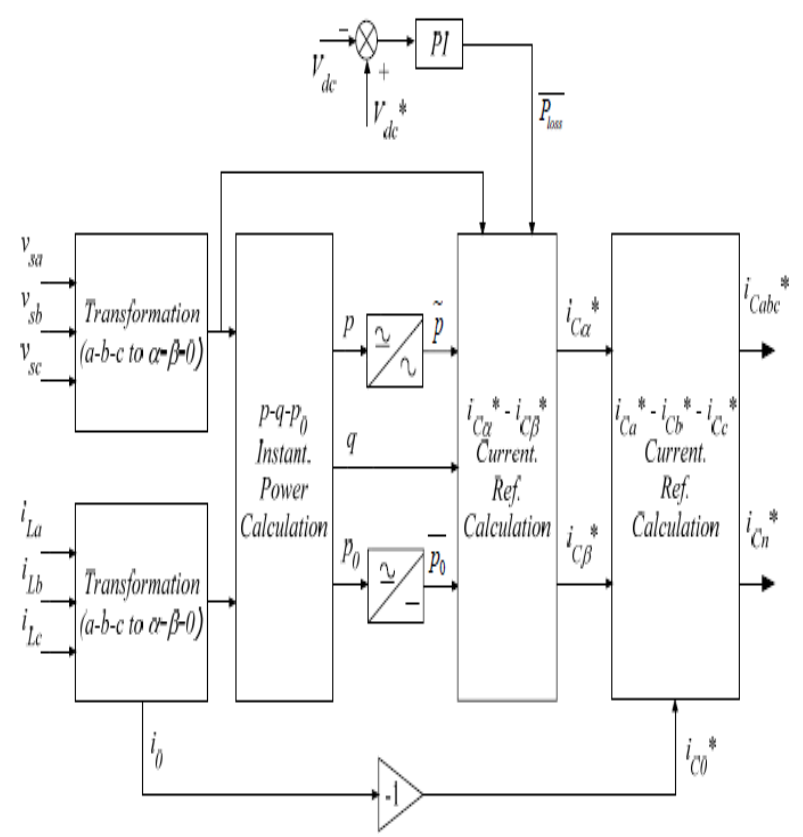

Figure (2):Reference current extraction with conventional p-q method.

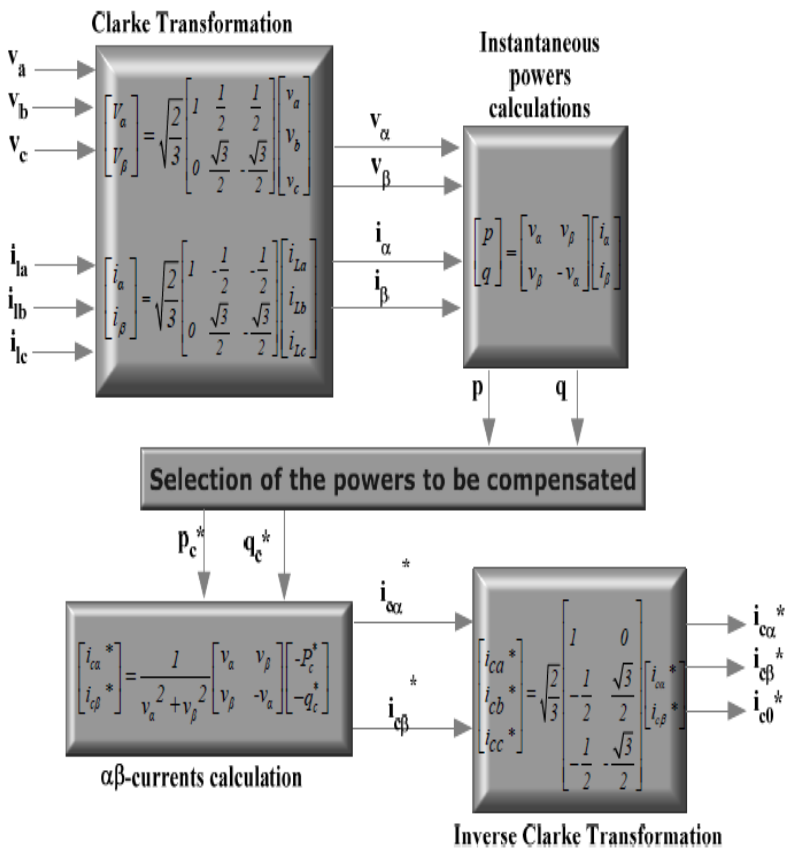

Figure (3): Control method for Shunt current compensation based on $\mathrm{p}-\mathrm{q}$ theory

$$
\begin{aligned}
& {\left[\begin{array}{l}
\mathrm{i}_{\alpha} \\
\mathrm{i}_{\beta}
\end{array}\right]=\left[\begin{array}{rrr}
1 & -\frac{1}{2} & -\frac{1}{2} \\
0 & \frac{\sqrt{3}}{2} & -\frac{\sqrt{3}}{2}
\end{array}\right]\left[\begin{array}{l}
\mathrm{i}_{\mathrm{L}_{\mathrm{a}}} \\
\mathrm{i}_{\mathrm{L}_{\mathrm{b}}} \\
\mathrm{i}_{\mathrm{L}_{\mathrm{c}}}
\end{array}\right]} \\
& {\left[\begin{array}{l}
\mathrm{p}_{\mathrm{q}} \\
\mathrm{q}
\end{array}\right]=\left[\begin{array}{cc}
\mathrm{v}_{\alpha} & \mathrm{v}_{\beta} \\
\mathrm{v}_{\beta} & -\mathrm{v}_{\alpha}
\end{array}\right]\left[\begin{array}{l}
\mathrm{i}_{\alpha} \\
\mathrm{i}_{\beta}
\end{array}\right]}
\end{aligned}
$$

Each of these powers has dc component (1st component) and ac component (2nd component) as shown in (4).

$$
\begin{aligned}
& \mathrm{p}=\overline{\mathrm{p}}+\tilde{\mathrm{p}} \\
& \mathrm{q}=\overline{\mathrm{q}}+\tilde{\mathrm{q}}
\end{aligned}
$$

For reactive and harmonic compensation, the entire reactive power and ac component of active power are utilized as the reference power. The reference currents in $\alpha-\beta$ coordinates are calculated by using (5).

$$
\begin{aligned}
& {\left[\begin{array}{l}
\mathrm{i}_{\mathrm{c} \alpha}^{*} \\
\mathrm{i}_{\mathrm{c} \beta}^{*}
\end{array}\right]=\frac{1}{\mathrm{v}_{\alpha}^{2}+\mathrm{v}_{\beta}^{2}}\left[\begin{array}{cc}
\mathrm{v}_{\alpha} & \mathrm{v}_{\beta} \\
\mathrm{v}_{\beta} & -\mathrm{v}_{\alpha}
\end{array}\right]\left[\begin{array}{l}
-\mathrm{p}_{\mathrm{c}}^{*} \\
-\mathrm{q}_{\mathrm{c}}^{*}
\end{array}\right]}
\end{aligned}
$$

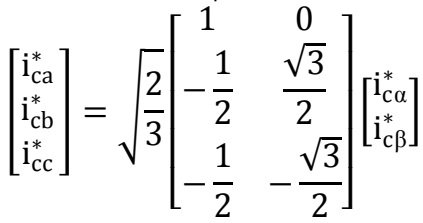

In addition PLL (Phase locked loop) employed shunt filter tracks automatically, the system frequency and fundamental positive-sequence component of three phase generic input signal. Appropriate design of PLL allows proper operation under distorted and unbalanced voltage conditions. Controller includes small changes in positive sequence detector as harmonic compensation is mainly concentrated on three phase four wire [9]. As we know in three-phase three wire, $\mathrm{V}_{\mathrm{a}}, \mathrm{V}_{\mathrm{b}}, \mathrm{V}_{\mathrm{c}}$ are used in transformations which resemble absence of zero sequence component and it is given in Equation (7). Thus in three phase four wire it was modified as $\mathrm{V}_{\alpha}{ }^{\prime}, \mathrm{V}_{\beta}$ ' and it is given in Equation (8).

$$
\begin{aligned}
& {\left[\begin{array}{l}
\mathrm{v}_{\mathrm{a}}^{\prime} \\
\mathrm{v}_{\mathrm{b}}^{\prime} \\
\mathrm{v}_{\mathrm{c}}^{\prime}
\end{array}\right]=\sqrt{\frac{2}{3}}\left[\begin{array}{cc}
1 & 0 \\
-\frac{1}{2} & \frac{\sqrt{3}}{2} \\
-\frac{1}{2} & \frac{\sqrt{3}}{2}
\end{array}\right]\left[\begin{array}{l}
\mathrm{v}_{\alpha}^{\prime} \\
\mathrm{v}_{\beta}^{\prime}
\end{array}\right]} \\
& {\left[\begin{array}{c}
\mathrm{v}_{\alpha}^{\prime} \\
\mathrm{v}_{\beta}^{\prime}
\end{array}\right]=\frac{1}{\mathrm{i}_{\alpha}^{\prime 2}+\mathrm{i}_{\beta}^{\prime 2}}\left[\begin{array}{cc}
\mathrm{i}_{\alpha}^{\prime} & -\mathrm{i}_{\beta}^{\prime} \\
\mathrm{i}_{\beta}^{\prime} & \mathrm{i}_{\alpha}^{\prime}
\end{array}\right]\left[\begin{array}{l}
\overline{\mathrm{p}}^{\prime} \\
\overline{\mathrm{q}}^{\prime}
\end{array}\right]}
\end{aligned}
$$

\section{INSTANTANEOUS ACTIVE AND REACTIVE CURRENT METHOD (Id-Iq)}

The load currents $i_{\mathrm{La}}, \mathrm{i}_{\mathrm{Lb}}$ and $\mathrm{i}_{\mathrm{Lc}}$ are tracked upon which Park's transformation is per-formed to obtain corresponding d-q axes currents $i_{L d}$ and $i_{L q}$ as given in (9), where $\omega$ is rotational speed of synchronously rotating $d-q$ frame. According to id-iqcontrol strategy, only the average value of d-axis component of load current should be drawn from supply. Here $\mathrm{i}_{\mathrm{Ld} 1 \mathrm{~h}}$ and $\mathrm{i}_{\mathrm{Lq} 1 \mathrm{~h}}$ indicate the fundamental frequency component of $i_{L d}$ and $i_{L q}$. The oscillating 
Vol. 5, Issue 3, March 2017

components $i_{L d}$ and $i_{L q}$, i.e., $i_{L d n h}$ and $i_{L q n h}$ are filtered out using low-pass filter.

$$
\begin{gathered}
{\left[\begin{array}{l}
\mathrm{i}_{\mathrm{Ld}} \\
\mathrm{i}_{\mathrm{Lq}}
\end{array}\right]=\left[\begin{array}{ll}
\mathrm{i}_{\mathrm{Ld} 1 \mathrm{~h}} & \mathrm{i}_{\mathrm{Ldnh}} \\
\mathrm{i}_{\mathrm{Lq} 1 \mathrm{~h}} & \mathrm{i}_{\mathrm{Lqnh}}
\end{array}\right]} \\
{\left[\begin{array}{c}
\mathrm{i}_{\mathrm{Ld}} \\
\mathrm{i}_{\mathrm{Lq}}
\end{array}\right]=\left[\begin{array}{cc}
\sin w \mathrm{t} & \cos w \mathrm{t} \\
-\cos w t & -\sin w t
\end{array}\right]\left[\begin{array}{ccc}
1 & -\frac{1}{2} & -\frac{1}{2} \\
0 & \frac{\sqrt{3}}{2} & -\frac{\sqrt{3}}{2}
\end{array}\right]\left[\begin{array}{l}
\mathrm{i}_{\mathrm{La}} \\
\mathrm{i}_{\mathrm{Lb}} \\
\mathrm{i}_{\mathrm{Lc}}
\end{array}\right](9)}
\end{gathered}
$$

The currents $i_{\text {Ldnh }}$ and $i_{\text {Lqnh }}$ along with $i_{d 1 h}$ are utilized to generate reference filter currents $\mathrm{i}_{\mathrm{cd}} *$ and $\mathrm{i}_{\mathrm{cq}} *$ in $\mathrm{d}-\mathrm{q}$ coordinates, followed by inverse Park transformation giving away the compensation currents $\mathrm{i}_{\mathrm{ca}} *, \mathrm{i}_{\mathrm{cb}} *, \mathrm{i}_{\mathrm{cc}} *$ and $\mathrm{i}_{\mathrm{cn}} *$ in the four wires as described in (10) and (11).

$$
\begin{gathered}
{\left[\begin{array}{c}
\mathrm{i}_{\mathrm{ca}}^{*} \\
\mathrm{i}_{\mathrm{cb}}^{*} \\
\mathrm{i}_{\mathrm{cc}}^{*}
\end{array}\right]=\left[\begin{array}{ccc}
\sin \mathrm{wt} & \cos \mathrm{wt} & 1 \\
\sin \left(\mathrm{wt}-\frac{2 \pi}{3}\right) & \cos \left(w \mathrm{t}-\frac{2 \pi}{3}\right) & 1 \\
\sin \left(\mathrm{wt}+\frac{2 \pi}{3}\right) & \cos \left(\mathrm{wt}+\frac{2 \pi}{3}\right) & 1
\end{array}\right]\left[\begin{array}{l}
\mathrm{i}_{\mathrm{cd}}^{*} \\
\mathrm{i}_{\mathrm{cq}}^{*} \\
\mathrm{i}_{\mathrm{c} 0}^{*}
\end{array}\right]} \\
\mathrm{i}_{\mathrm{cn}}^{*}=\mathrm{i}_{\mathrm{ca}}^{*}+\mathrm{i}_{\mathrm{cb}}^{*}+\mathrm{i}_{\mathrm{cc}}^{*}
\end{gathered}
$$

The reference signals thus obtained are compared with the actual compensating filter currents in a hysteresis comparator, where the actual current is forced to follow the reference and provides instantaneous compensation by the APF [10] on account of its easy implementation and quick prevail over fast current transitions. This consequently provides switching signals to trigger the IGBTs inside the inverter. Ultimately, the filter provides necessary compensation for harmonics in the source current and reactive power unbalance in the system.

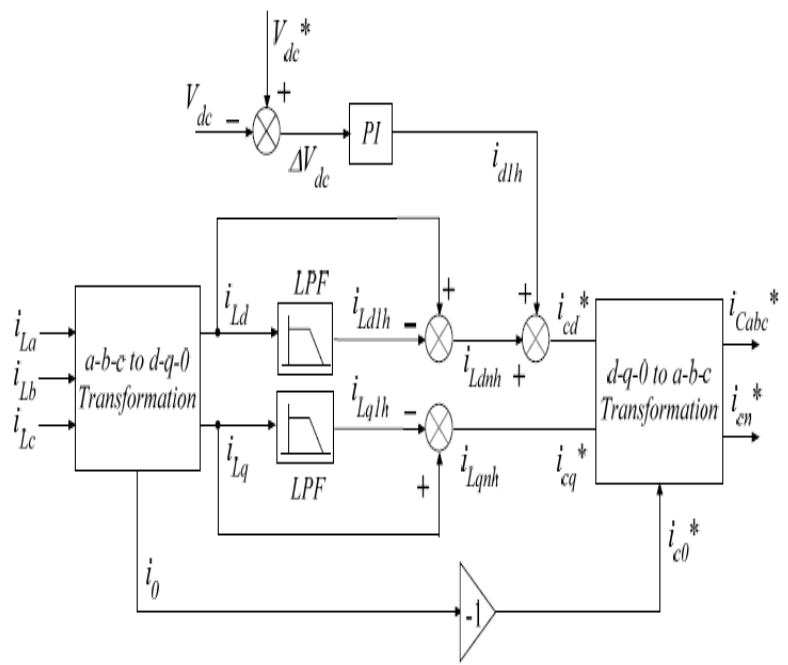

Figure (4): Reference current extraction with Id-Iq method

\section{PI CONTROLLER}

PI control is needed for non-integrating processes, meaning any process that eventually returns to the same output given the same set of inputs and disturbances. A Ponly controller is best suited to integrating processes. The control scheme of our system consist of PI controller, limiter, three phase sin wave generator for reference current generation and generation of switching signal. The DC link voltage regulates the peak value of reference current. The actual capacitor voltage is thus compared with the reference values. The PI controller processes the error signal which results in zero steady error in tracking the reference current signal. The output of PI controller is taken as peak value of system current $\left(\mathrm{I}_{\max }\right)$, which is composed of to components i.e. the fundamental active power component of load current and the loss component of active power filter; to maintain the average capacitor voltage to a constant value. The $\mathrm{I}_{\max }$ is multiplied by the unit sign vector in phase with the respective source voltages to obtained the reference compensating current.

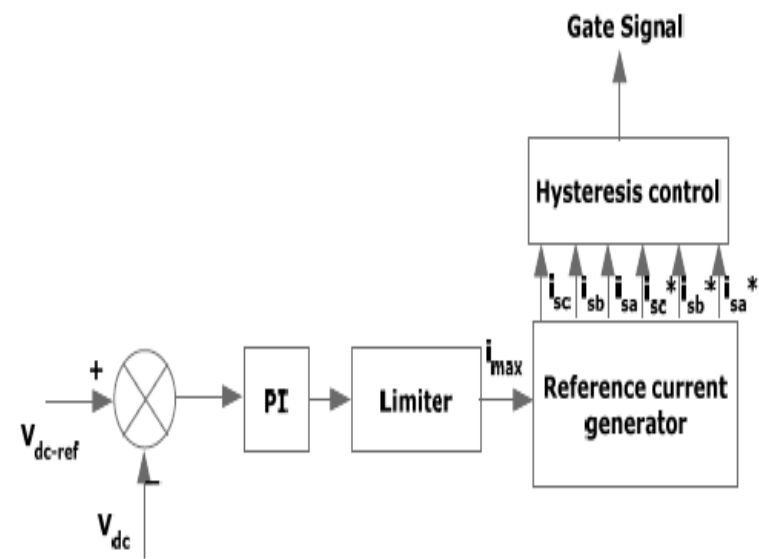

Figure (5): Conventional PI controller.

The estimated refer-ence currents (Isa*, Isb*, Isc*) and sensed actual currents (Isa, Isb, Isc) are compared at a hysteresis band, which gives the error signal for the modulation technique. Thus the operation of convertor switches is excited by the error signals. In this current control circuit configuration, the source/supply currents Isabcare made to follow the sino-soidal reference current Iabc, within a fixed hysteretic band. The width of hysteresis window determines the source current pattern, its harmonic spectrum and the switching frequency of the devices.

\section{CONCLUSION}

Thus the paper gives the idea of improvement in power quality using shunt active power filter. Basically we calculated the refrence current values of the system using active and reactive power and current control strategies with the help of PI controller. Now these reference current values are compared to the main current (system current) values by using hysteresis comparator and thus the resultant value of current to the shunt active power filter. Hence the compensating current is injected in the system through the three leg SAPF. Hence using P-Q technique 


\section{IJIREEICE \\ International Journal of Innovative Research in \\ Electrical, Electronics, Instrumentation and Control Engineering \\ ISO 3297:2007 Certified \\ Vol. 5, Issue 3, March 2017}

and SAPF the quality or the stability of the system is increase and we have stable and error free system.

\section{REFERENCES}

[1] Leszek S. Czarnecki," Instantaneous Reactive Power p-q Theory and Power Properties Of Three-Phase Systems"IEEE Transactions on Power Delivery, Vol. 21, No.1, Jan. 2006, pp. 362-367

[2] SanguRavindra, Dr.V.C.Veera Reddy, Dr.S.Sivanagaraju," Design of Shunt Active Power Filter to eliminate the harmonic currents and to compensate the reactive power under distorted and or imbalanced source voltages in steady state" International Journal of Engineering Trends and Technology- Volume2Issue3- 2011.

[3] Suresh Mikkili, Anup Kumar Panda,"Instantaneous Active and Reactive Power and Current Strategies for Current Harmonics Cancellation in 3-ph 4-Wire SHAF with Both PI and Fuzzy Controllers" Energy and Power Engineering, 2011, 3, 285-298.

[4] Md. AshfanoorKabir and UpalMehbub,"Synchronous detection and digital control of shunt active power filter in power quality improvement'IEEE 2011.

[5] A.Subramaniya Siva , M.Bhavani,"Mitigation of Harmonics by Shunt Active Power Filter using Synchronous Detection Method" International Journal of Engineering Trends and Technology (IJETT) - Volume 4 Issue 6- June 2013.

[6] Viki S. Patel,"Power Quality Improvement using Active shunt Power filter using PI Controller"2014 IJEDR | Volume 2, Issue 1 | ISSN: 2321-9939.

[7] B. Venkata Ramana, S. Dayasagar Chowdary, G. Venkata Ratnam," Analysis of Active and Passive Power Filters For Power Quality Improvement under Different Load Condtion" International Journal of Advanced Research in Electrical, Electronics and Instrumentation Engineering (An ISO 3297: 2007 Certified Organization) Vol. 3, Issue 8, August 2014.

[8] D. Sandeep Kumar, G.VenuMadhav," Power quality improvement with a shunt active power filters using MATLAB/ Simulink" International journal of innovative research in electrical, electronics, instrumentation and control engineering Vol. 3, Issue 1, January 2015.

[9] R.V.L. NarayanaDivakar, P.Kishore, CH.Ravi Kumar, V.Madhu Kishore, V.PradeepKumar,'Power Quality Improvement of NonLinear Load by Using Instantaneous P-Q Theory" International Journal of Electrical and Electronics Research ISSN 2348-6988 (online) Vol. 3, Issue 1, pp: (346-353), Month: January - March 2015.

[10] Ravi PrakashVishvakarma and SatyaveerGupt,"Power Quality Improvement with Shunt and Hybrid APF Using PI and Hysteresis Current Controllers: Performance Comparison" Intl J EnggSciAdv Research 2015 Mar;1(1):113-120.

[11] Mohit Bajaj, SiddhartRautela and AshwiniSharma,"A Comparative Analysis of Control Techniques of SAPF under Source Side Distribution"2016 ICCPCT.

[12] Mark McGranaghan," Active filter design and specification for control of harmonics in industrial and commercial facilities". 